\title{
Development of Independence among Future Primary School Teachers by Applying Interactive Learning Methods
}

\author{
Rotova Natalia Alexandrovna ${ }^{1}$
}

${ }^{\prime}$ Candidate of Pedagogical Sciences, Senior Lecturer of the Chair of the Theory and Methods of Preschool and Primary Education of Surgut State Pedagogical University, Surgut, Russia Email:rotowa.n@yandex.ru

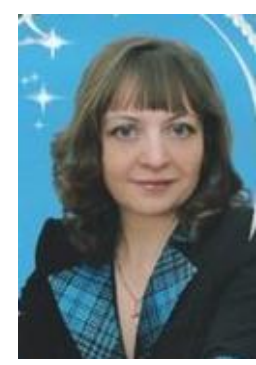

\begin{abstract}
The necessity to develop independence among future primary school teachers during the process of studying in higher education institutions is substantiated. The essentials of independence notion are disclosed as efforts of students aimed at reaching the goals single-handedly. The results of the ascertaining experiment on defining the level of self-organisation expertise maturity confirm the necessity to develop conscientious attitude towards the process of mastering the knowledge, expertise, skills and primary experience in professional sphere. The results of the ascertaining experiment reveal the following: 21 students from 30 second-year students (major in Primary Education) while solving a case task represented by a problem situation substantiate their solution on the basis of empirical experience, not on the theoretical knowledge. Consequently, it is relevant to train future primary school teachers to organise their own learning activity. Interactive learning methods are suggested to solve the problem of independence development among the future primary school teachers. Pedagogical conditions of efficient interactive learning forms in higher education institutions are substantiated and it launches the development mechanism for such personality feature as independence.
\end{abstract}

Keywords: Educational activities, Interactive forms of training.

Citation | Rotova Natalia Alexandrovna (2018). Development of Independence among Future Primary School Teachers by Applying Interactive Learning Methods. Journal of Education and e-Learning Research, 5(2): 118-121.

History:

Received: 9 May 2018

Revised: 1 June 2018

Accepted: 5 June 20187

Published: 8 June 2018

Licensed: This work is licensed under a Creative Commons

Attribution 3.0 License $(\mathrm{cc}) \mathbf{E Y}$

Publisher:Asian Online Journal Publishing Group
Funding: This study received no specific financial support.

Competing Interests: The author declares that there are no conflicts of interests regarding the publication of this paper.

Transparency: The author confirms that the manuscript is an honest, accurate, and transparent account of the study was reported; that no vital features of the study have been omitted; and that any discrepancies from the study as planned have been explained.

Ethical: This study follows all ethical practices during writing.

\section{Contents}

1. Introduction

2. Method

4. Conclusion and Discussion 


\section{Introduction}

Distinctive features of cognitive independence, the essentials of intellectual independence and creative independence are represented in psychological and pedagogical literature, particularly in the researches of P.I. Pidkasistiy (Pidkasistiy, 1998). O. A. Kirillova indicates the necessity to cultivate learning independence during the learning process at school using the complex of problem-based tasks in her thesis research. She specifies the notion of learning independence understanding it as a personality feature which is manifested particularly in the learning activity. It comprises cognitive, activity and need-motivational components including the goal setting, initiative search of reaching the goal, making a decision in a choice situation which is based not only on the teacher's requirement, but primarily on self-motivation (Kirillova, 2008). In the explanatory dictionary by D.N. Ushakov the independence is defined as the ability of a personality to act independently, to opinionate independently, being initiative, resolute (Ushakov, 1935-1940). Considering the psychological basis of an independent personality L.S. Vygotskiy substantiates commitment to act as an essential characteristic which means that independently overcoming difficulties a personality gains the experience that allows further development (Leontyev, 1975). It is necessary therefore during the studies at higher education institutions to use such teaching methods which would allow the students to reveal the initiative in making decisions on a pedagogical problem situation, develop the solution plan and relate it to the cultural norms. Notably culture encourages a person to find sense and become sure of the propriety of actions. As far as methodological basis of personality independence is concerned, we shall address to the researches of A.N. Leontyev (Leontyev, 1975) who while considering psychological issues connected to the disclosure of the ground of learning conscientiousness indicated that particularly motives define the learning conscientiousness, revealed the unity principle of activity, conscience and personality which means that conscientious development of personality occurs within the activity process. Nevertheless, motivating the very mechanism of foundation of such a personality feature as independence, S.A. Pakulina proves that it is formed exactly in the condition of overcoming difficulties. The self-analysis, in its turn, as an integral component of activity encourages the development of independence, allows the personality to be active and motivates to further activity. It is especially important during the process of studying in a higher education institution to learn how to self-organize one's own learning activity. S.A. Pakulina calls independence a characteristic of person's maturity, a condition under which the person becomes a conscientious reflexive personality (Pakulina, 2008). On the basis of analysing psychological and pedagogical literature the researcher draws a conclusion that the common ground of independence is socio-cultural, it encourages the constant professional development of future educators. It is relevant for a future primary school teacher not only to possess the expertise of self-organisation and selfdevelopment, but also to be able to organise learning and disciplinary activity of primary schoolers in accordance with the requirements of Federal Education Standards of Primary General Education (FGOS NOO) for solving the pedagogical professional tasks according to Federal Education Standards of Higher Education (FGOS VO). Therefore the expertise to make decisions independently in the process of pedagogical activity, to understand the responsibility for the decisions made, to plan the future self-development activity becomes a particularly burning issue for students. Exactly this kind of expertise is considered to be the outer side of students' independence in the higher education institution named after I.M. Vorotilkina. She relates the need-motivational sphere, students' efforts aimed at reaching the goals single-handedly (Vorotilkina, 2012) to the inner component of independence which confirms the main direction of students' independent work that includes the development of conscientious attitude towards the process of mastering the knowledge, expertise, skills and primary experience in professional sphere.

\section{Method}

We used 'Self-organisation Activity Questionnaire' Feather and Bond to define the level of self-organisation expertise maturity, the adaptation in the Russian language is made by Mandrikova (2010). The research 'Conformity to Plan Scale' was performed. It discloses the level of possessing by the future primary school teachers the expertise to plan their activity and systematically follow the developed plan. The research 'Conformity to Plan Scale' revealed the disposition to use while organising their activity the supporting tools of time-management. Thus, in order to disclose the expertise of future primary school teachers in structuring their activity proper, in particular, to reveal what makes the ground for their own pedagogical position - empirical experience or theoretical knowledge - we carried out the questionnaire among the second-year students (major in Primary Education). The research was carried out with the second-year students (major in Primary Education), the quantity of participants is 30 students. The results of the research performed are reflected in Table 1.

\section{Implications}

Table-1. Assessment of the Level of Self-organisation, Planning, Structuring Expertise Maturity (the Results of the Ascertaining Stage of the Experiment)

\begin{tabular}{l|l|l|l}
\hline Criterion, index / Levels & Low level, \% & Medium level, \% & High level, \% \\
\hline $\begin{array}{l}\text { 'Self-organisation' scale: the tendency to use the supporting } \\
\text { tools of time-management while organising the activity }\end{array}$ & 30 & 50 & 20 \\
\hline 'Conformity to Plan' scale: the expertise to plan the activity and \\
follow the developed plan systematically & 20 & 60 & 20 \\
\hline $\begin{array}{l}\text { The expertise to structure the activity, to substantiate their } \\
\text { own pedagogical position on the basis of theoretical knowledge, } \\
\text { not on empirical experience (questionnaire, case task) }\end{array}$ & 70 & 20 & 10 \\
\hline
\end{tabular}

The results of the research allowed to find out the following: the future primary school teachers are far better at planning their activity and at systematically following their plan - 80 percent of tested students showed medium and high level, the expertise of self-organisation is developed a bit worse -80 percent. The students are bad at 
structuring the activity professionally, they substantiate their pedagogical position not on theoretical ground, but on the basis of their empirical experience (Rotova, 2018).

\section{Conclusion and Discussion}

While summarizing the results of the ascertaining stage of the experiment we can see that the second-year students (major in Primary Education) in order to solve a case task which is a problematic situation substantiate their solution on the basis of empirical experience, not on theoretical knowledge. Consequently, it is necessary to train future primary school teachers to organise their own studying activity. The professor at the higher education institution during the studying process needs to structure classroom studies in such a way that they would contain the solution of situational tasks, problem issues. It encourages students to be substantially involved in the process of studies and develops the communication skills. Touching upon the system of self-studies for students the professor needs to provide methodological recommendations for studying process. They shall contain the plans of seminar classes, materials for checking self-studies.

It is essential to carry out classroom studies for students in an interactive way to develop their independence. Interactive learning methods are based on interaction. As it is defined by S. Ozhegov interaction is a mutual connection of two generations, mutual support (Ozhegov and Shvedova, 1999). T.V. Semenovskikh, A.V. Petrovskiy consider the fact that interacting sides are connected by cause-and-effect dependence to be its distinctive feature (Semenovskikh, 2013). Foreign psychologists and educators (D. Mead, G. Bloomer) regard interaction to be a continuous dialogue in the process of which people observe, comprehend each other's intentions and react to them placing themselves at each other's side. It is notable that T.V. Semenovskikh, firstly, distinguishes two types of interaction: cooperation which is teamwork aimed at reaching one goal, and competition, rivalry which is when goal and opinions are opposite, and secondly, she defines a distinctive feature of interaction as situationality (Semenovskikh, 2013). Exactly the situation determines the duration, intensity and depth of interaction. The process of interaction supposes the existence of a common goal, the participants need to develop a common strategy to reach the result. Not only the expertise to structure and reason proper opinion on the issue researched comes to the foreground, but also the ability to hear the opinion of other participants of interaction. If the studying process structuring in the higher education institution is aimed at teaching the basics of communication (Rotova, 2017) and independent decision-making during the solution of practice-oriented tasks, games which means that there is modeling of real professional situation in the game - then such interactive forms will be based on the simulation model. Such forms may include working in small groups, role-play and businessplay, solution of case situations, inviting specialists, watching films, interviews, visiting exhibitions, theatrical performances, 'Decision tree' method, 'P.R.E.S. Formula' method, trainings, debates, disputes, creation of 'microworlds' representing a sort of 'laboratory' where the participants not only model the situation, but also are suggested to consider the consequences for all of them. Thus, we can define the necessary efficiency conditions of interactive learning methods at higher education institutions on the assumption of their essentials as follows: - compulsory theoretical grounding of a practical solution or one's own position represented;

- detailed studies of theoretical material, mastering the methods of work with theoretical information;

- application of individual tasks which are of self-testing or testing character in order to boost students' interest;

- selection of testing material to carry out micro-researches aimed at developing the expertise to define the problem proper and plan its solutions;

- working out problem issues by the professor, suggestion of different variants of their solutions;

- the necessity to highlight the involvement of all students into discussion and, consequently to think over the distribution of roles in the group, different forms of work on the part of a professor;

- constant control for the situation of students' group interaction, during the answer it is necessary to plan the participation of each student in the group work and work out the methods of rewarding active participants;

- suggesting tasks on developing certain solutions of a problem considered on the basis of mastering common ways of designing and planning.

Thus, the application of interactive learning methods at higher education institutions launches the mechanism of developing such a personality feature as independence. Interactive forms carried out exactly under professor's control contribute to the fact that necessary conditions for adopting cultural norms of communication are created during their realisation. The adoption of different courses of action in practice-oriented professional situations takes place through it. The application of interactive learning methods at higher education institution by a professor affords students an opportunity to predict their course of action in a real situation and see the result of the decision having been made which is a condition for forming conscientious attitude towards studies among students. A significant stage in the independence development is an expertise to purposefully select theoretical information and structure it. It brings the necessity to master common methods of critical analysis and reasoning. Firstly, a professor shall use the opportunity to structure the lecture applying problem issues and situations, and, secondly, to direct the cognitive process through scientific search. It may be realised by means of informative problem-solving lecture, webinar classes, conference. A previously shot brief video-lecture enhanced by photos that demonstrate material being studied would perfectly serve to revise the material mastered. Thus, we may affirm that the development of such personality feature as independence among students enables forming an expertise relevant for the improvement of cognitive professional competence component for future primary school teachers.

The specific character of a primary school teacher has some distinctive features:

- commitment of a primary school teacher to the process of communication in the situation when children trust their teacher in a special way. The teacher is the most significant adult in new social conditions of a primary schooler's development;

- teacher's expertise to distinguish inner problems important to a child in different sorts of their address to the teacher (Rotova, 2017).

Consequently, the teacher has to be prepared to interact with all the participants of learning process and, first of all, with primary schoolers. By application of such interactive method as case technologies the communication skills are formed on the basis of considering a common course of action while solving communicative tasks. The 
development of orientational component can be stated, as the problem is pointed out, the supposed consequences are structured and ranged by the chosen way of communication. Shall we consider a situation. The bell has rung, the lessons are over, fourth-form students have come to the school assembly hall to decorate it for a celebration. However, it is overwhelmingly noisy, some children adjust wall newspapers, others communicate loudly. How to organize children quickly to decorate the hall actively for the celebration?

It is possible to solve the situation in a usual manner by just giving them a task. Nevertheless, taking into consideration that children eagerly communicate with each other and enjoy it, they do not want to change their activity, we can suppose that the result of such a solution would be temporary. So the teacher would have to become a supervisor if one does not pay attention to the pupils' involvement and their role into a communicative situation. A group of students designed a simple solution concerning the role of all participants of the communication. As children have brought wall newspapers to demonstrate, the teacher comes to a wall newspaper and asks loudly pointing to it: 'Who has made this wall newspaper?' Transferring their attention to their product of activity the teacher highlights a mistake and then announces the purpose of work without any pause (Rotova, 2017).

There is also a possibility to realise an operational component of the competence during a business-play when students are in the situation of the adequate communicative methods' choice necessary to solve the situation. Particularly, an opportunity of a substantiated choice of different solutions to the problem stated, the search of the right solution emerges by means of modeling various conditions of professional activity. The efficiency of the method is in the fact that 'borders fade' between an abstract, theoretical character of a subject studied and real character of professional activity, students receive the need to master the expertise of analysing the situation. Thus, we can state that the interactive learning methods considered encourage the development of independence of future primary school teachers and effective formation of professional competence components.

\section{References}

Kirillova, O.A., 2008. Development of learning independence of pupils by means of a problem tasks complex. Author's Abstract. Thesis. Candidate of Pedagogical Sciences. - Shadrinsk.

Leontyev, A.N., 1975. Activity. Consciousness. Personality. / A.N. Leontyev. - M.: Politizdat. pp: 304.

Mandrikova, Y.Y., 2010. Development of a questionnaire on self-organisation of activity. Psychological Testing, 2: 87-1 11.

Ozhegov, S.I. and N.Y. Shvedova, 1999. Explanatory Dictionary of the Russian language: 80 ooo words and phraseological expres sions / Russian Academy of Sciences. V.V. Vinogradov's Russian Language Institute. - 4th Edn., Enlarged. - M.: Azbukovnik. pp: 944.

Pakulina, S.A., 2008. Peculiarities of adaptation process for students of pedagogical higher education institution. Education and Science: Izvestiya of Ural Branch of the Russian Academy of Sciences, 6: 66-67.

Pidkasistiy, P.I., 1998. Pedagogics. Learning guide for students of pedagogical higher education institutions and pedagogical colleges. M.: Pedagogical association of Russia. pp: 175.

Rotova, N.A., 2017. Development of communicative competence of future primary school teachers by means of case technologies // Modern problems of contemporary education: Experience and innovations. Materials of the Research-to-Practice Conference (Distance) with International Participation. Publishing editor A. Yu. Nagornova. pp: 354-357.

Rotova, N.A., 2017. On the issue of developing communicative competence of a future primary general school teacher. European Journal of Social Sciences, 4: 241-245.

Rotova, N.A., 2018. Workshop the presentation of the profession 'primary school teacher' as means of activating professional and personal self-identification. Pedagogics and Contemporary Education: Traditions, Experience and Innovations: Materials of the International Research-to-Practice Conference. Penza. Nauka i Prosvesshtcheniye. pp: 144-147.

Semenovskikh, T.V., 2013. Pedagogical psychologies. Learning guide. Tyumen: Tyumen State University Publishing Office. pp: 308.

Ushakov, D.N., 1935-1940. Ushakov's explanatory dictionary. Explanatory dictionary of Russian language. / Edited by D.N. Ushakov. M.: State Institution 'Sov. encycl.'; OGIZ (Association of State Book and Magazine Publishers); State Publishing Office of Foreign and National Dictionaries, 1935-1940, 4 . Retrieved from http://enc-dic.com/ushakov/Samostojatelnost-67713.html.

Vorotilkina, I.M., 2012. Independence of students in educational process. Higher Education in Russia, 3: 92-97. View at Google Scholar 